\title{
Geographic variation in mortality among individuals with youth-onset diabetes mellitus across the world
}

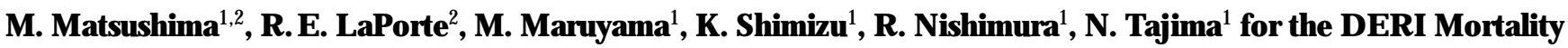 \\ Study G roup*
}

${ }^{1}$ D epartment of Internal M edicine (III), J ikei U niversity School of M edicine, Tokyo, Japan

${ }^{2}$ D epartment of E pidemiology, U niversity of Pittsburgh, Pennsylvania, U SA

Summary The aim of this study was to evaluate the geographic variation in mortality among individuals with youth-onset insulin-dependent diabetes mellitus (IDDM) across the world. The study was based on the currently available ID D M incidence and mortality data. M ortality data for diabetes in the 0-24 year age group were obtained from World $\mathrm{H}$ ealth O rganization (W H O ) statistics. The mortality rates were adjusted for the frequency of occurrence of IDDM by dividing the mortality rates by the IDDM incidence rates which were obtained from the WHO D iaM ond project. There was a more than 10 -fold geographic variation in mortality between the developed countries and E astern E uropean populations. The areas with the highest mortality rates were located in Japan, E astern E urope and R ussia. The areas having the best outcome associated with ID D M were North- ern E urope, Central E urope, and Canada. A n ecological study demonstrated a relationship between the incidence-adjusted mortality (estimated case-fatality) with ID D M incidence itself (Spearman's correlation coefficient $=-0.45$ ) as well as infant mortality and life expectancy at birth. These data demonstrated the possibility of an enormous geographic variation in mortality of youth-onset diabetic patients even in developed countries. It is important to note that these excess deaths are potentially preventable. The ecological study also suggested that the mortality differences may be in part related to overall and diabetes related care. [D iabetologia (1997) 40: 212-216]

Keywords IDDM, mortality, incidence, epidemiology, life expectancy.
Individuals who have insulin-dependent diabetes mellitus (IDDM ) are at a markedly increased risk of death [1-3], the reasons for which are not known. The D iabetes E pidemiology R esearch I nternational (DERI) G roup has recently demonstrated a considerable variation across countries and the possible risk factors for the excess mortality in Japan and the

Received: 23 M ay 1996 and in final revised form: 240 ctober 1996

Corresponding author: M. M atsushima, MD, M PH, Department of Internal Medicine (III), Jikei U niversity School of Medicine, 3-25-8 Nishishimbashi, M inato-ku, Tokyo 105, Japan

A bbreviations: IDDM, Insulin-dependent diabetes mellitus; DE R I, D iabetes E pidemiology R esearch International.

* See A cknowledgements.
U nited States in contrast to I srael and Finland [4-6]. These geographic differences highlight countries and societies such as Japan and the USA where mortality is excessive and could be reduced. D isappointingly, other than for these four countries, there are few other directly comparable data in the world. A primary reason being the expense of establishing large population-based registries with mortality follow-up.

In the current report, therefore, we have employed routinely collected death certificates to identify countries which appear to have remarkably low mortality or high mortality rates to serve as indicators of potential excessive mortality. To achieve this we evaluated the diabetes mortality rates before 25 years of age in 24 regions (including whites and blacks in the $U$ nited States) by using statistics from the World $\mathrm{H}$ ealth $\mathrm{O}$ rganization (WHO) [7]. We should be extremely cautious when using mortality data based on death 
certificates which may often be unreliable and include exclusively the deaths from diabetic acute complications. It is essential to compare the degree of underestimation for diabetes mortality among countries. A nother difficulty in employing diabetes mortality rates is that the primary determinant of the overall mortality rates is the number of people who have diabetes under age 25 years. Thus, countries with higher diabetes mortality rates, not unexpectedly, are those who have more cases of diabetes in this age group. This is particularly true for IDDM as there is an enormous ( 30 -fold) international variation in the frequency of the disease [8]. Therefore, for meaningful comparisons to be made concerning cross-population differences in diabetes mortality, one has to control for differences in the number of patients who have diabetes. To accomplish this, we employed the incidence-adjusted mortality (mortality per incidence or case fatality). The aim of this study was to examine the degree to which there is a variation in incidence-adjusted IDDM mortality among countries.

\section{Subjects and methods}

\section{D ata source}

D iabetes E pidemiology R esearch International (DERI) M ortality study. A s the mortality statistics from WHO are based upon death certificates, we had to be cautious, since it is possible that death certificates for some IDDM patients may not include diabetes as a cause of death. I $f$ there are large differences across countries with regard to reporting diversity on the death certificate, then it is difficult to determine if apparent crosscountry differences are the result of nations varying in the inclusion of diabetes on the death certificate. We were able to examine this question in the DERI mortality study. The DER I mortality study is a follow-up of youth-onset IDDM patients in Finland, I srael, J apan and the U nited States. D etailed information about the DERI study has been described elsewhere $[4,5]$. By reviewing the death certificates for people known to have IDDM in the DERI cohorts, we were able to determine if there was differential reporting on the death certificate across these countries. A s will be demonstrated, having diabetes on the death certificates primarily represented diabetic acute-complication-related deaths, and there was a consistent degree of reporting across countries.

Incidence data. The current study used incidence data collected through the effort of W H O D iaM ond project [9-26]. E ach registry in the D iaM ond project was conducted in a standardized manner. The criteria for IDDM are described as follows: 1) clinical diagnosis by a physician; 2) placed on daily insulin injections before 15th birthday; 3 ) resident in the area of registration at the time of the first insulin administration.

M ortality data. M ortality data for the $0-24$ year age group in 1989 or 1990 were obtained from the W H O World H ealth Statistics A nnual [7]. We assumed that it would be rare for NIDDM patients to die before 25 years of age. Therefore, the mortality in the 0-24 year age group would most likely demonstrate the mortality almost exclusively due to IDDM. We limited the populations to developed countries and Eastern $\mathrm{E}$ urope following the definition by W HO [7].

\section{Statistical analysis}

The current study first evaluated the IDDM mortality rates for ages 0 to 24 years. Then mortality rates were assessed after adjustment for the frequency of ID D M in each country. The adjustment was performed by dividing the IDD M mortality rates from the W H O statistics by the incidence rates from $\mathrm{D}$ iaM ond project.

Incidence - adjusted mortality =

number of deaths from a disease

number of diagnosed cases of that disease

(estimated case-fatality rate (\%))

B oth incidence rates and mortality rates were age-adjusted for world population [7]. The weighting used for each age category were 0.0466 for 0 year of age, 0.1845 for 1 - 4 years, 0.3972 for $5-14$ years, and 0.3717 for $15-24$ years.

The second component of this study was to relate socioeconomic indices to the IDDM mortality rates. The socioeconomic indices used in the analysis were gross national product (GNP) per capita, life expectancy at birth, infant mortality from the WHO's 12 global indicators to monitor and evaluate the strategy for health [7, 27-32]. To examine and summarize the association between the variables, the Spearman's rank correlation coefficients on which extreme points had small effect were employed. A II statistical procedures were conducted in SA S 6.08 [33].

\section{Results}

Extrapolation from the DERI study. The percentage of all deaths before 25 years of age with the term "diabetes" on their death certificates as a cause of death in four countries, Finland, Israel, Japan, and the U nited States, which participated in the DERI mortality study, were $59 \%, 25 \%, 57 \%$ and $64 \%$, respectively. A pproximately $60 \%$ (78/135) of total deceased patients in the cohorts had the term "diabetes" on their death certificates. Except for Israel, whose sample size was quite small ( 6 deaths before 25 years of age), the proportions of those with the term "diabetes", were quite similar among the cohorts. Therefore, it can be assumed that we could apply the data from death certificate to the comparison of early mortality among developed countries in the world, as at least in countries with a sufficient number of deaths there was little difference.

Causes of death between those with "diabetes" on a death certificate and those without were compared. N ot unexpectedly, $80 \%$ (37/46) of those who died of diabetic acute complications had "diabetes" on their death certificates. In contrast, only $29 \%$ of those who died of traumatic events had "diabetes" on their 
death certificates. Thus, "diabetes" on the death certificate represented diabetic acute-complication-related deaths which were typically thought to be preventable.

Variation in mortality and case-fatality rates among countries. The variation of mortality is shown in Table 1 . In addition, Table 1 exhibits the rate ratios for case fatality rates using $\mathrm{N}$ orway as the standard population. We selected N orway as a basis as it had a high incidence rate, and mortality was determined on a large number of patients. The second reason is that it had a lower case-fatality rate compared to most of the other countries.

Table 1 demonstrates that there was enormous geographic variation in mortality ratios in IDDM across the world. Individuals with IDDM in Sofia, Bulgaria, were 10 times more likely to die than those in Norway prior to the age of 25 years.

The adjusted-mortality rates can be roughly grouped into the lowest, those having a mortality ratio up to twice that of Norway, medium, up to 4 times that of Norway, highest, up to 10 times that of Norway. A s indicated earlier, these differential mortality rates represent primarily diabetic acute-complication-related deaths. The areas having the highest mortality ratios were located in Japan, Eastern E urope and $\mathrm{R}$ ussia. The areas having the best outcome associated with IDDM were Northern E urope, Central E urope, and Canada.

Correlation between case fatality rate and socioeconomic indicators. Bivariate plotting of adjusted-mortality rates, and socioeconomic indicators and incidence rates are shown in Figure 1. Infant mortality and life expectancy at birth were correlated with the case-fatality rate, indicating that the differences in diabetes deaths may be indicative of general population health. IDDM incidence itself was significantly correlated with the case-fatality rate where Spearman's rank correlation coefficient was -0.44 $(p<0.02)$. Thus, in areas where there are a large number of cases, mortality is low.

\section{Discussion}

International comparative studies offer an excellent method for identifying areas of high diabetic acutecomplication-related deaths; areas where preventive measures could be implemented. U p to now, however, only the DER I study has been available representing only four countries. B y employing frequency adjusted diabetes mortality statistics we were able to extend the geographic comparisons for the four populations to 24 populations. The results demonstrated an almost 10 -fold variation in the risk of dying across countries, with young Japanese and E astern E uropeans having
Table 1. ID D M incidence, incidence-adjusted mortality (casefatality) and rate ratio of adjusted mortality in 24 regions in the world

\begin{tabular}{|c|c|c|c|}
\hline & $\begin{array}{l}\text { Incidence } \\
\text { rate } \\
(/ 100,000)\end{array}$ & $\begin{array}{l}\text { Incidence- } \\
\text { adjusted } \\
\text { mortality } \\
\text { (E stimated } \\
\text { case-fatality } \\
(\%))\end{array}$ & $\begin{array}{l}\text { M ortality } \\
\text { rate ratio }\end{array}$ \\
\hline \multicolumn{4}{|l|}{ L owest [R ef] } \\
\hline L uxembourg [10] & 10.5 & 0.00 & 0.00 \\
\hline I celand [11] & 9.4 & 0.00 & 0.00 \\
\hline A ustria [10] & 7.7 & 0.00 & 0.00 \\
\hline Spain $[10,12]$ & 10.8 & 0.35 & 0.55 \\
\hline Canada [13] & 16.9 & 0.56 & 0.87 \\
\hline Norway [10] & 20.8 & 0.65 & 1.00 \\
\hline Netherlands [10] & 11.0 & 0.77 & 1.18 \\
\hline A ntwerp, B elgium [10] & 9.8 & 0.78 & 1.21 \\
\hline U K [14] & 13.5 & 0.84 & 1.30 \\
\hline D enmark [10] & 21.5 & 0.85 & 1.31 \\
\hline I taly $[10,15,16]$ & 11.4 & 0.91 & 1.40 \\
\hline France [10] & 7.8 & 0.94 & 1.44 \\
\hline G reece [10] & 7.0 & 1.06 & 1.63 \\
\hline Finland [17] & 35.3 & 1.17 & 1.80 \\
\hline G ermany [18] & 7.4 & 1.27 & 1.96 \\
\hline Sweden [19] & 24.4 & 1.28 & 1.96 \\
\hline \multicolumn{4}{|l|}{ M edium } \\
\hline U SA, whites [20-22] & 15.4 & 1.39 & 2.14 \\
\hline U SA, blacks [20-22] & 11.5 & 1.86 & 2.86 \\
\hline Poland [10] & 5.7 & 2.28 & 3.50 \\
\hline Portugal $[10,23]$ & 7.5 & 2.50 & 3.84 \\
\hline \multicolumn{4}{|l|}{ H ighest } \\
\hline Japan $[13,24]$ & 1.8 & 3.10 & 4.77 \\
\hline M oscow, R ussia [25] & 5.6 & 3.65 & 5.62 \\
\hline Bucharest, R umania [10] & 5.1 & 6.41 & 9.86 \\
\hline Sofia, Bulgaria [26] & 6.7 & 6.45 & 9.92 \\
\hline
\end{tabular}

$\mathrm{R}$ ate ratios of incidence-adjusted mortality were calculated based on the mortality of N orway. In countries where IDDM incidence rates were measured in several areas, the mean of all areas was employed. Italy; Sardinia, A osta, Vicenza, E astern Sicily, Turin, U mbria, Lombardia, and Lazio. Spain; Madrid, and Catalonia. Canada; Prince E dward Island, and M ontreal. G reece; $A$ thens, and five northern regions. U SA ; A llegheny County, Jefferson County, and Philadelphia. Poland; three cities, and nine western provinces. Japan; O saka, and Hokkaido.

by far the highest mortality. A s the IDDM incidence rates were measured in the comparable way, they are considered reliable. The other measurement in the current study is the mortality rate. The results from the DER I mortality study suggest that there is a high congruence across countries concerning mortality of IDDM patients before 25 years of age with a similar proportion of patients being reported on death certificates. It is unlikely that a more than 10 -fold difference in mortality risk could be attributed to differential completion of death certificates.

O ne could argue that the differential seen across countries was purely an artifact. However, there is some evidence suggesting that this is not the case. The first is that their patterns are entirely consistent with the in-depth approach taken with the smaller 

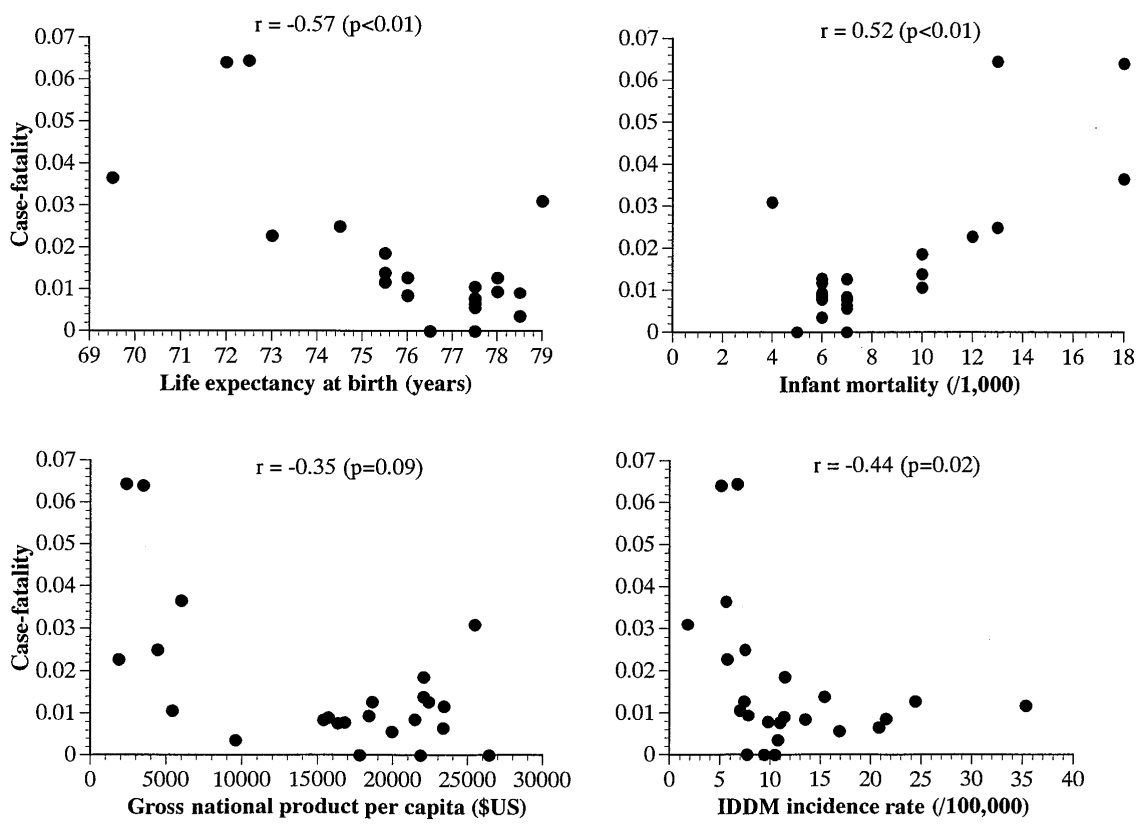

Fig. 1. Bivariate plotting of G NP per capita, life expectancy at birth, infant mortality and IDD M incidence, and incidence-adjusted mortality rates [27-32]. $r$ = Spearman's rank correlation coefficient

DER I mortality study where by far the lowest mortality was in Finland followed by the U nited States whites, U nited States blacks and Japanese. A Iso, a 10 -fold difference in morality rates is unlikely to be attributed to an artifact.

However, we should discuss the assumptions and the limitations of the current ecological study. First, there is a concern that the W H O statistics do not separate IDDM and NIDDM. However, it can be assumed that the vast majority of diabetic deaths in the younger age group were exclusively due to IDDM since over $90 \%$ of diabetic patients who develop diabetes under 20 years of age are IDD M [34]. M oreover, NIDDM in general does not have such a markedly increased mortality compared with ID D M. The other concern is that WH O mortality statistics are based on the information from death certificates. There are limitations in mortality statistics from death certificates; for example, in general, diabetes is not likely to be listed on the death certificate and thus is not considered a cause of death. H owever, if the populations are limited to developed countries and the deaths are limited to those before 25 years of age, the mortality data from death certificates may reflect the true values although they may be underestimated, if our experience of the DERI study can be extrapolated to other developed countries. Therefore, the variation in mortality found in this study may reflect the variation in case-fatality from deaths which are highly attributed to diabetes itself,

in particular, diabetic acute complications under the assumptions described above.

It should be emphasized, again, that we dealt with the deaths exclusively from acute diabetic complications. The reason being that the deaths from chronic complications were in most part neglected since the deaths were limited to those before 25 years of age and based on death certificates. Similarly, other causes of deaths such as accident and suicide may not be considered. Therefore, we have difficulty in referring to the variation in mortality from chronic complications, accident and suicide by using the current data.

Considering these issues under assumptions, we concluded that there may be a considerable geographic variation in IDDM case-fatality across the world and hypothesized the cause-effect relationship between the low incidence rate and the high case-fatality rate. 0 ver a 10 -fold variation in ID D M case-fatality indicates that a large number of ID D M patients world-wide die unnecessarily.

Countries with the higher incidence of ID D M tended to have the lower mortality. This may reflect the greater expertise of the physicians in treating diabetic children, thus the better the outcome and the lower risk of dying. If a paediatrician, for example, in his/ her lifetime sees only one case in J apan, there is probably a very different pattern of care than for a paediatrician diagnosing 5-10 cases per year as in Finland. Moreover, the mortality statistics used in the study did not include the deaths in older age groups; therefore, the effect of poor medical care on the overall mortality from IDDM may be magnified when considering the mortality in older age groups.

In conclusion, the study based on WHO statistics evaluated the case-fatality rates in a number of regions in the world, and demonstrated the possibility of an enormous geographic variation in mortality of 
IDDM patients even among developed countries. Since the current study is ecological by using the mortality data derived from death certificates, the results should be interpreted with caution. H owever, we can at least make the hypothesis to prevent premature deaths among people with diabetes. This study also suggested that the mortality differences were in part related to overall and diabetes-related care. It is important to continue to monitor the mortality associated with IDDM worldwide as most of the deaths are probably preventable, and to complete the analytical approach to identify the risk factors for premature death among individuals with IDDM .

A cknowledgements. D E R I M ortality Study G roup;

Finland: J. Tuomilehto, R . L ounamaa, P. L ounamaa, A . R eunanen, E. Tuomilehto-W olf, and $\mathrm{H}$. A kerblom.

I srael: Z. Laron, M. K arp, and O. Gordon

A llegheny County, PA , U SA : R . E . L aPorte, A . L. D rash, L.H . Kuller, D.J. Becker, J.S. D orman, I.F. Gower, T.J. O rchard, T.J. Songer, E.S. Tull, E.J. B arinas, Y. Chang, and R.J. Vergona. Japan: T. K itagawa, N. Tajima, M . A ono, S. A ono, I . H ibi, Y. I keda, G. I sshiki, M . K awamura, K . K ida, Y. K ohno, H . M aruyama, M. M aruyama, M. M atsushima, N. M atsuura, E. M iki, E. M imura, R . N ishimura, K. Shimizu, A . Takeda and T. Toyota.

\section{References}

1. Borch-Johnsen K (1989) The prognosis of insulin-dependent diabetes mellitus. $D$ anish $M$ ed B ull 36: 336-348

2. K rolewski A, Warram J, Christlieb A (1985) Onset, course, complication and prognosis of diabetes mellitus. In: $\mathrm{M}$ arble $A$, K rall L P, B radley R F, C hristlieb A R, Soeldner J S (eds). J oslin's D iabetes M ellitus. 12th ed. Philadelphia, PA , L ea \& Febiger, pp 251-277

3. Panzram G (1984) E pidemiologic data on excess mortality and life expectancy in insulin-dependent diabetes mellitus. Crit Rev Exp Clin E ndocrinol 82: 93-100

4. The D iabetes E pidemiology R esearch International M ortality Study G roup (1991) M ajor cross-country differences in risk of dying for people with ID D M. D iabetes Care 14: 49-54

5. The D iabetes E pidemiology R esearch International M ortality Study G roup (1991) International evaluation of cause-specific mortality and ID D M. D iabetes Care 14: 55-60

6. Patrick SL, Tajima N, L aPorte RE, K itagawa T for the D iabetes E pidemiology R esearch International (DERI) Japan-U.S. M ortality Study Group (1992) A comparison of renal disease mortality among individuals with insulin-dependent diabetes mellitus (IDDM) in Japan and Allegheny County, PA, the U nited States. J Japan Diab Soc 35: 993-1000

7. World Health O rganization (1991) World health statistics annual. G eneva

8. L aPorte R E, Tajima N, A kerblom H K et al. (1985) G eographic differences in the risk of insulin-dependent diabetes mellitus: the importance of registries. Diabetes Care 8 [Suppl 1]:101-107

9. WHO DIA M OND Project Group (1990) W H O multinational project for childhood diabetes. D iabetes Care 13: 1062-1068

10. G reen A, G ale EA, Patterson CC for the EURODIA B A CE study (1992) Incidence of childhood-onset insulin-dependent diabetes mellitus: the EURODIA B A CE study. Lancet 339: 905-909

11. H elgasson T, D anielsen R, Thorsson A V (1992) Incidence and prevalence of type 1 (insulin-dependent) diabetes mellitus in Icelandic children 1970-1989. Diabetologia 35: 800-803

12. R ios M S, M oy CS, Serrano R M, A sensio A M , L abat M ET, R omero G Z, H errera J (1990) I ncidence of type 1 (insulin-dependent) diabetes mellitus in subjects $0-14$ years of age in the $\mathrm{C}_{0}$ munidad of M adrid, Spain. D iabetologia 33: 422-424
13. R ewers $M, L$ aPorte $R E, K$ ing $H$, Tuomilehto J for the $D$ iabetes E pidemiology Research International Study Group (1988) Trends in the prevalence and incidence of diabetes: I nsulin-dependent diabetes mellitus in childhood. World Health Stat 13: 1062-1068

14. M etcalfe M A , B aum J D (1991) Incidence of insulin-dependent diabetes in children aged under 15 years in the B ritish I sles during 1988. B M J 302: 443-447

15. D iabetes E pidemiology R esearch I nternational (DERI) Study Group (1990) The epidemiology and immunogenetics of IDDM in Italian-heritage populations. D iabetes M etab R ev 6: 63-69

16. B runo G, M erletti F, Pisu E, Pastore G, M arengo C, Pagano G (1990) Incidence of IDDM during 1984-1986 in population aged less than $30 \mathrm{yr}$. R esidents of Turin, I taly. D iabetes Care 13: 1051-1056

17. Tuomilehto J, L ounamaa $R$, Tuomilehto-Wolf $E$, R eunanen $A$, Virtala E, K aprio EA, A kerblom HK and the Childhood Diabetes in Finland (D iM e) Study Group (1992) E pidemiology of childhood diabetes mellitus in Finland - background of a nationwide study of type 1 (insulin-dependent) diabetes mellitus. D iabetologia 35: 70-76

18. K arvonen M, Tuomilehto J, Libman I, L aPorte R (1993) A review of the recent epidemiological data on incidence of type 1 (insulin-dependent) diabetes mellitus worldwide. Diabetologia 36: 883-892

19. Nystrom L, D ahlquist G, R ewers M , Wall S (1990) The Swedish childhood diabetes study. A $n$ analysis of the temporal variation in diabetes incidence 1978-1987. Int J E pidemiol 19: 141-146

20. R ewers M, Stone R A , L aPorte R E et al. (1989) Poisson regression modeling of temporal variation in incidence of childhood insulin-dependent diabetes mellitus in Allegheny County, Pennsylvania, and W ielkopolska, Poland, 1970-1985. A m J Epidemiol 129: 569-581

21. Tull ES, R oseman J M, Christian CL (1991) E pidemiology of childhood IDD M in U.S. V irgin I slands from 1979 to 1988. E vidence of an epidemic in early $1980 \mathrm{~s}$ and variation by degree of racial admixture. Diabetes Care 14: 558-564

22. Lipman TH (1993)The epidemiology of type I diabetes in children 0-14 yr of age in Philadelphia. D iabetes Care 16: 922-925

23. R odrigues FJ C, M oura LS, Pinto $B$, Gomes $L, C$ arvalheiro $M$, R uas M M A (1992) Incidence of childhood type 1 (insulin-dependent) diabetes in Coimbra, Portugal, 1987-91. Diabetologia 35 [Suppl 1]:A 130 (A bstract)

24. Sasaki A , O kamoto N (1992) E pidemiology of childhood diabetes in O saka D istrict, Japan, using the documents from the medical benefits system specific for childhood diabetes. Diabetes R es Clin Pract 18: 191-196

25. L ebedev N, C uraeva T, Sergeev A , G ubanov N , D edov I (1992) E pidemiology of type 1 and type 2 diabetes in the young population of M oscow. Diabetologia 35 [Suppl 1]:A 130 (A bstract)

26. A tanasova M, Koprivarova K (1992) Incidence of diabetes mellitus type 1 in Bulgarian children. D iabetologia 35 [Suppl 1]:A 131 (A bstract)

27. Central Intelligence A gency (1991) The World Factbook 1991. Washington, U.S. G overnment Printing O ffice

28. E ncyclopædia B ritanica (1991) E ncyclopædia B ritanica World D ata A nnual 1991. Chicago, Encyclopædia Britanica

29. The Statesman's Year-B ook 1989-1990 (1990) New York, St. M artin's Press

30. E uropa Publications (1991) The E uropa World Year Book 1991 E uropa Publications L imited, L ondon

31. International M onetary Fund (1991) International Financial Statistics Yearbook 1991 Washington, I nternational M onetary Fund

32. PlanE con (1991) R anking of Eastern R epublican/R egional M arkets by Size M easured by 1989 G NP B ased on Purchasing Power Parity. Washington, PlanE con, Inc

33. SA S I nstitute Inc. (1990) SA S/STA T U ser's G uide, Version 6, 4th ed. Volume1\& 2. Cary, NC, SA S I nstitute Inc

34. L aakso M, Pyorala K (1985) A ge of onset and type of diabetes. D iabetes Care 8: 114-117 